\title{
A study of the different parameters in acute and chronic Budd-Chiari syndrome
}

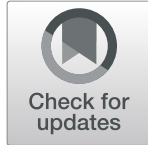

Ramin Niknam¹, Nemattellah Hajizadegan ${ }^{1}$, Vahid Mohammadkarimi ${ }^{{ }^{*+}}$ and Laleh Mahmoudi ${ }^{3^{* \dagger}}$ (D)

\begin{abstract}
Background: Budd-Chiari syndrome (BCS) is a rare and potentially life-threatening vascular disease of the liver. There are a few studies on the differences between acute and chronic BCS in clinical and laboratory characteristics, as well as the outcomes, so we designed this research to study the different parameters in acute and chronic BCS. Diagnosis of BCS was made using Doppler ultrasound, magnetic resonance imaging, and venography. Patients with BCS were then divided into chronic and acute groups based on both imaging characteristics and disease duration. Finally, the outcomes, clinical features, and laboratory parameters of acute and chronic BCS were compared.

Results: In total, 60 patients were included in this study, of whom $28.3 \%$ and $71.7 \%$ had acute and chronic BCS, respectively. According to clinical features, spontaneous bacterial peritonitis (PR 1.289; 95\% Cl 1.115-1.489; $P=$ 0.001 ) and jaundice (PR 1.308; 95\% Cl 1.148-1.490; $P<0.001$ ) were significantly associated with chronic than acute BCS. According to laboratory parameters, the levels of international normalized ratio (INR) (PR 0.953; 95\% Cl 0.9180.989; $P=0.012)$, blood urea nitrogen (BUN) (PR 0.996; 95\% Cl 0.993-1.000; $P=0.039$ ), and model for end-stage liver disease (MELD) score (PR 1.024; 95\% Cl 1.012-1.037; $P<0.001$ ) in chronic group were significantly higher than in the acute BCS. The hospital length of stay (LOS) and mortality rate between the two groups did not differ significantly.

Conclusions: This study showed that the spontaneous bacterial peritonitis, jaundice, increased levels of MELD score, INR, and BUN were significantly associated with the chronic group compared with the acute group. The hospital LOS and mortality rate between the two groups did not differ significantly. Further research is recommended to clarify this issue.
\end{abstract}

Keywords: Budd-Chiari syndrome, Liver, Acute, Chronic, Outcome

\section{Background}

Budd-Chiari syndrome (BCS) is a rare and potentially life-threatening disorder caused by a partial or complete occlusion from small hepatic veins till inferior vena cava including the main hepatic veins [1-3]. The true

\footnotetext{
* Correspondence: Vahid.mohammadkarimi@gmail.com;

Mahmoudi_|@sums.ac.ir

${ }^{\dagger}$ Vahid Mohammadkarimi and Laleh Mahmoudi contributed equally to this work.

${ }^{2}$ Department of Internal Medicine, School of Medicine, Shiraz University of Medical Sciences, Shiraz, Iran

${ }^{3}$ Department of Clinical Pharmacy, School of Pharmacy, Shiraz University of Medical Sciences, Shiraz, Iran

Full list of author information is available at the end of the article
}

incidence of BCS is unknown due to its rarity, and various results have been reported in different regions [3, 4].

Based on the onset of the disease in most studies, BCS is classified as acute (less than 6 months) and chronic (more than 6 months), and these two types of BCS differ in clinical manifestations, treatment, and prognosis $[3,5,6]$.

Although some studies suggest that clinical presentations have little relationship with the actual duration of BCS [7], acute BCS is usually associated with severe symptoms, poor prognosis, and high mortality, while chronic BCS in most patients has an insidious onset and present with cirrhosis and surface varicose veins. Therefore, accurate diagnosis is essential for a rational treatment, to improve symptoms and increase survival [5]. 
The signs and symptoms of BCS vary, so this diagnosis should be considered in any patient with acute or chronic liver disease [2, 7]. Most physicians differentiate between the acute and chronic forms of the disease based solely on the patient's history, which makes it difficult to diagnose BCS with insidious presentation. Therefore, imaging techniques such as Doppler ultrasound, magnetic resonance imaging (MRI), and computed tomography are necessary to diagnose BCS, as well as to differentiate acute from chronic disease [5]. Hepatic venography is recommended if the clinical suspicion of BCS is high (the presence of hepatomegaly, abdominal pain, and ascites with unknown cause), and there are no typical findings in other imaging [8].

There is controversy about the association of clinical and laboratory characteristics with the actual duration of $\mathrm{BCS}$. On the other hand, there are few reports comparing clinical features, laboratory parameters, and outcomes between acute and chronic BCS [1, 5, 7]. Therefore, we conducted this study with the aim of comparing outcomes, clinical features, and laboratory parameters in different types of BCS in Namazi Hospital, as the main referral center for patients with liver disease in southern Iran.

\section{Methods}

\section{Participants and groups}

A cross-sectional study was performed at a referral hospital affiliated with Shiraz University of Medical Sciences between 2016 and 2020. All participants who were referred to our hospital for diagnosis and treatment for BCS from other centers were included in the study. Exclusion criteria as conditions that could act as confounders were heart failure, non-cooperative patients, sinusoidal obstruction syndrome, liver transplantation, and hepatic cancer. All eligible patients were followed for types and clinical and laboratory parameters of BCS.

Final diagnosis of BCS as well as follow-up of patients was performed by a hepatologist. Necessary variables including age, sex, ethnicity, individual habits, etiology, clinical features, associated disorders, and laboratory data were recorded in the checklist. BCS participants were divided into acute and chronic groups according to the criteria identified below. Finally, clinical and laboratory parameters between acute and chronic BCS were compared.

\section{Diagnosis of BCS and its types}

All patients with suspected BCS were examined using Doppler ultrasound and MRI. The diagnosis of BCS was based on the presence of thrombosis in the hepatic veins or inferior vena cava, decreased or reversed flow in these veins, and dampening of hepatic vein spectral waveform. If the diagnosis of BCS could not be confirmed by previous two methods, direct venography was used for further examination. Patients with BCS were then divided into chronic and acute groups based on both imaging characteristics and disease duration. Chronic BCS was defined as a disease duration more than 6 months $[5,6]$ and replacement of the hepatic vein and/or inferior vena cava by collateral veins in Doppler ultrasound or the presence of MRI findings indicating chronic BCS including collateral veins, regenerative nodules, decreased T1- and T2-weighted signal intensity on unenhanced MRI, and delayed enhancement on contrastenhanced imaging because of replacement of parenchymal edema by fibrosis [8]. Acute BCS was defined as a disease onset of less than 6 months without evidence of chronicity in Doppler ultrasound and MRI.

The differentiation between hepatocellular carcinoma and regenerative nodules was based on imaging characteristics and alpha-fetoprotein levels. If the diagnosis was still unclear, a biopsy of the liver lesion was performed. Thrombophilia testing was performed to evaluate the underlying hypercoagulable states in all patients with BCS.

\section{Ethical approval/statement}

This research was carried out taking into account the ethics Declaration of the Helsinki research and was approved by the ethics committee of Shiraz University of Medical Sciences (IR.SUMS.MED.REC.1397.442). Written consent was obtained from all patients.

\section{Measurement of laboratory parameters}

Blood samples were taken to evaluate complete blood count, liver biochemical tests, partial thromboplastin time (PTT), international normalized ratio (INR), blood urea nitrogen (BUN), creatinine, and blood sugar for all participants. Jaundice was defined as the total serum bilirubin level greater than $2.5 \mathrm{mg} / \mathrm{dL}$. Paracentesis was performed to assess the albumin, protein, culture, cell counts, and differentiation for all patients with ascites. All laboratory parameters were tested under international standards, and blood samples were transported to the laboratory in less than an hour. Finally, serumascites albumin gradient (SAAG) and model for endstage liver disease (MELD) score was also calculated based on the results of lab data for all participants.

\section{Statistical analysis}

The data was stored in a SPSS software, version 25.0, Chicago, USA. Qualitative data analysis was performed using chi-square test. Quantitative data was expressed as the mean and standard deviation, and the differences between the groups were examined using two independent $t$ tests and Mann-Whitney test, where appropriate. Robust Poisson regression models were used to estimate 
prevalence ratio (PR) and 95\% confidence interval (CI) to evaluate the association of various independent clinical and laboratory variables on the types of BCS. The Kaplan-Meier method and log rank test was used for comparing hospital length of stay (LOS) between groups, defining in-hospital mortality as the main event. $P$ value lower than 0.05 was considered as significant difference.

\section{Results}

In total, 60 patients were included in this study, of whom 17 (28.3\%) had acute BCS and 43 (71.7\%) participants were considered as the chronic BCS group. The median/mean age (SD) was 37.5/37.68 (12.78) years ranging from 19 to 90 years. Twenty-one $(35.0 \%)$ and 39 (65.0\%) patients were male and female, respectively. Diagnosis was made in 58 patients based on Doppler ultrasound and MRI, while 2 patients underwent direct venography due to uncertain results in imaging studies. The most common predisposing factor of BCS was myeloproliferative neoplasms (8.3\%). Overall, 22 (36.7 \%) patients had Fars ethnicity and 19 (31.7 \%) were smokers. The demographic and clinical characteristics of the participants are shown in Table 1.

Although most of the patients were male, there was no significant difference compared to women in terms of acute or chronic BCS $(P=0.24)$. According to clinical features, jaundice in chronic BCS group was significantly higher than acute group $(P<0.001)$ but there was no significant difference in other variables between two groups. The comparison of clinical and demographic characteristics between acute and chronic BCS is shown in Table 2.

According to laboratory parameters, levels of PTT, INR, bilirubin, and end-stage liver disease (MELD) score in chronic BCS were significantly higher than acute group. There were no significant differences between the two groups in other laboratory variables such as hemoglobin, platelet, alanine transaminase (ALT), aspartate transaminase (AST), albumin, protein, and ascitic fluid parameters. The comparison of laboratory parameters between acute and chronic BCS is shown in Table 3.

Robust Poisson regression models was used for estimating the PRs and 95\% CIs to evaluate the association of various clinical and laboratory variables on the types of BCS. Spontaneous bacterial peritonitis (PR 1.289; 95\% CI 1.115-1.489; $P=0.001$ ) and jaundice (PR 1.308; 95\% CI 1.148-1.490; $P<0.001$ ) were significantly associated with chronic than acute BCS. However, other variables including gender, age, encephalopathy, gastrointestinal (GI) bleeding, and renal failure were not significantly associated with acute compared to chronic BCS group (Table 4).

According to laboratory parameters, the levels of INR (PR 0.953; 95\% CI 0.918-0.989; $P=0.012$ ), BUN (PR
Table 1 Demographic and clinical characteristics of participants with Budd-Chiari syndrome $(n=60)$

\begin{tabular}{|c|c|}
\hline $\begin{array}{l}\text { Gender } \\
\text { Male } \\
\text { Female }\end{array}$ & $\begin{array}{l}21(35.0 \%) \\
39(65.0 \%)\end{array}$ \\
\hline Age (years); mean \pm SD & $37.68 \pm 12.78$ \\
\hline $\begin{array}{l}\text { Ethnicity } \\
\text { Fars } \\
\text { Turke } \\
\text { Arabs } \\
\text { Lurs } \\
\text { Kurds } \\
\text { Baloch } \\
\text { Mazandarani } \\
\text { Turkomen }\end{array}$ & $\begin{array}{l}22(36.7 \%) \\
15(25.0 \%) \\
5(8.3 \%) \\
5(8.3 \%) \\
4(6.7 \%) \\
4(6.7 \%) \\
3(5.0 \%) \\
2(3.3 \%)\end{array}$ \\
\hline $\begin{array}{l}\text { Past medical history } \\
\text { Myeloproliferative neoplasms } \\
\text { Paroxysmal nocturnal hemoglobinuria } \\
\text { Myelodysplastic syndromes } \\
\text { Antiphospholipid syndrome } \\
\text { Protein C deficiency } \\
\text { Lymphoma } \\
\text { Positive human immunodeficiency virus } \\
\text { Systemic lupus erythematosus } \\
\text { Pseudotumor cerebri } \\
\text { Diabetes mellitus }\end{array}$ & $\begin{array}{l}5(8.3 \%) \\
3(5.0 \%) \\
2(3.3 \%) \\
1(1.7 \%) \\
1(1.7 \%) \\
1(1.7 \%) \\
1(1.7 \%) \\
3(5.0 \%) \\
1(1.7 \%) \\
3(5.0 \%)\end{array}$ \\
\hline Cigarette smoking & 19 (31.7\%) \\
\hline Alcohol use & $1220.0(\%)$ \\
\hline Abdominal pain & $46(76.7 \%)$ \\
\hline Jaundice & $29(48.3 \%)$ \\
\hline Ascites & $60(100.0 \%)$ \\
\hline Spontaneous bacterial peritonitis ${ }^{1}$ & $5(8.3 \%)$ \\
\hline Gastrointestinal bleeding ${ }^{1}$ & $16(26.7 \%)$ \\
\hline Encephalopathy & $14(23.3 \%)$ \\
\hline Renal failure & $12(20.0 \%)$ \\
\hline Hospital length of stay (days); mean \pm SD & $11.22 \pm 7.98$ \\
\hline Mortality & $6(10.0 \%)$ \\
\hline
\end{tabular}

${ }^{1}$ Spontaneous bacterial peritonitis was defined as ascitic fluid polymorphonuclear leukocyte count $\geq 250$ cells $/ \mathrm{mm}^{3}$ and positive ascitic fluid culture; gastrointestinal bleeding including hematemesis and melena

0.996; 95\% CI 0.993-1.000; $P=0.039)$, and MELD score (PR 1.024; 95\% CI 1.012-1.037; $P<0.001$ ) in chronic group were significantly higher than in the acute BCS. However, the levels of other variables including platelet, PTT, total bilirubin, and ascitic fluid parameters did not differ significantly between the two groups (Table 5).

The median/mean (SD) hospital LOS in patients with acute BCS was 12/13.29 (10.042) days and in chronic BCS patients was 9/10.40 (6.97) days. The Kaplan-Meier method and log rank test for comparing hospital LOS between acute and chronic BCS patients showed that there was no significant difference between the two groups $(P=0.34)$. Hospital LOS curves for patients with acute and chronic BCS are shown in Fig. 1. The inhospital mortality rate was $1(5.9 \%)$ and $5(11.6 \%)$ in 
Table 2 Comparison of clinical and demographic characteristics between acute $(n=17)$ and chronic $(n=43)$ Budd-Chiari syndrome (BCS)

\begin{tabular}{|c|c|c|c|}
\hline Variables & Acute BCS; $N(\%)$ & Chronic BCS; $N$ (\%) & $P$ value \\
\hline $\begin{array}{l}\text { Gender }^{2} \\
\text { Male } \\
\text { Female }\end{array}$ & $\begin{array}{l}4(23.5 \%) \\
13(76.5 \%)\end{array}$ & $\begin{array}{l}17(39.5 \%) \\
26(60.5 \%)\end{array}$ & 0.241 \\
\hline Age (years); mean $\pm S D$ & $34.47 \pm 11.07$ & $38.95 \pm 13.30$ & 0.224 \\
\hline $\begin{array}{l}\text { Ethnicity }{ }^{\mathbf{1}} \\
\quad \text { Fars } \\
\text { Others }\end{array}$ & $\begin{array}{l}7(41.2 \%) \\
10(58.8 \%)\end{array}$ & $\begin{array}{l}15(34.9 \%) \\
28(65.1 \%)\end{array}$ & 0.649 \\
\hline Abdominal pain ${ }^{1}$ & $13(76.5 \%)$ & $33(76.7 \%)$ & 0.982 \\
\hline Jaundice $^{1}$ & $2(11.8 \%)$ & $27(62.8 \%)$ & $<0.001$ \\
\hline Dyspnea $^{1}$ & $4(23.5 \%)$ & $15(34.9 \%)$ & 0.394 \\
\hline Peripheral edema ${ }^{1}$ & $8(47.1 \%)$ & $25(58.1 \%)$ & 0.437 \\
\hline Fever $^{1}$ & $4(23.5 \%)$ & $14(32.6 \%)$ & 0.492 \\
\hline Vomiting $^{1}$ & $13(76.5 \%)$ & $25(58.1 \%)$ & 0.184 \\
\hline Weight loss ${ }^{1}$ & $13(76.5 \%)$ & $27(62.8 \%)$ & 0.311 \\
\hline Encephalopathy ${ }^{1}$ & $2(11.8 \%)$ & $12(27.9 \%)$ & 0.183 \\
\hline Gastrointestinal bleeding & $2(11.8 \%)$ & $14(32.6 \%)$ & 0.101 \\
\hline Spontaneous bacterial peritonitis $^{1}$ & $0(0.0 \%)$ & $5(11.6 \%)$ & 0.142 \\
\hline Renal failure $^{1}$ & $1(5.9 \%)$ & $11(25.6 \%)$ & 0.086 \\
\hline Cigarette smoking ${ }^{1}$ & $3(17.6 \%)$ & $16(37.2 \%)$ & 0.142 \\
\hline Alcohol use $^{1}$ & $1(5.9 \%)$ & $11(25.6 \%)$ & 0.081 \\
\hline
\end{tabular}

${ }^{1}$ Chi-square test

${ }^{2} T$ test

patients with acute and chronic BCS, respectively, but there was no significant difference between the two groups $(P=0.45)$. There was no significant association between the predisposing causes of BCS and the increase in in-hospital mortality. The mean (SD) age of patients who died in hospital was 35.50 (6.25) years, and there was no significant association between patients' age and increased mortality $(P=0.66)$.

\section{Discussion}

$\mathrm{BCS}$ is a rare vascular disease of the liver with heterogeneous clinical manifestations caused by obstruction of hepatic venous outflow. According to the etiology of the disease, BCS is classified as primary and secondary. Primary BCS is caused by acquired conditions such as myeloproliferative neoplasms, hereditary conditions such as Factor V Leiden, and systemic prothrombotic conditions. Secondary BCS is caused by vascular compression due to pyogenic infectious process or benign and malignant tumors $[1$, $2]$. Regardless of the cause of the venous outflow obstruction, increased hepatic sinusoidal pressure and portal hypertension occur rapidly, leading to ischemic damage to the hepatocytes, followed by nodular regeneration, fibrosis, and eventually cirrhosis. In addition, large regenerative nodules may in turn lead to compression of intrahepatic veins $[1,4]$.

This study is the first report to compare the clinical features, laboratory parameters, and outcomes between acute and chronic BCS from Iran. This cross-sectional study showed that spontaneous bacterial peritonitis and jaundice were significantly associated with the chronic group compared with the acute group. The study also showed that levels of MELD score, INR, and BUN in chronic BCS was significantly higher than in the acute group. There was no significant difference between the outcomes of the two groups in terms of hospital LOS and mortality. In our patients the most common predisposing factor for BCS were myeloproliferative neoplasms, paroxysmal nocturnal hemoglobinuria, and systemic lupus erythematosus (Table 1)

The definitions of acute and chronic of BCS are not clearly defined [9]; however, most studies have classified the BCS with an onset of less than 6 months as acute and more than 6 months as chronic $[3,5,6]$. When BCS is suspected, color Doppler ultrasound is typically the first imaging procedure with high sensitivity and specificity [8]. Doppler ultrasound, MRI, and computed tomography are usually sufficient to diagnose BCS. Liver biopsy is only useful if the thrombosis is limited to the small intrahepatic veins and the large vessels appear 
Table 3 Comparison of laboratory parameters between acute $(n=17)$ and chronic $(n=43)$ Budd-Chiari syndrome (BCS)

\begin{tabular}{|c|c|c|c|c|}
\hline Variables & Acute BCS; $N(\%)$ & Chronic BCS; $N$ (\%) & $P$ value & Normal range \\
\hline White blood cells; $\mu l^{1}$ & $8386.47 \pm 3412.33$ & $8837.21 \pm 5014.17$ & 0.902 & $4000-10,000$ \\
\hline Hemoglobin; $\mathrm{g} / \mathrm{dL}^{2}$ & $11.51 \pm 1.98$ & $11.43 \pm 2.31$ & 0.901 & $12-16$ \\
\hline Platelet; $\mu \mathbf{l}^{1}$ & $257,058.82 \pm 228,189.47$ & $155,441.86 \pm 121,008.32$ & 0.075 & $140,000-400,000$ \\
\hline PTT; seconds ${ }^{1}$ & $37.34 \pm 4.44$ & $45.73 \pm 17.63$ & 0.016 & $25-35$ \\
\hline$I N R^{* 1}$ & $1.77 \pm 0.71$ & $3.04 \pm 2.16$ & 0.003 & $<1.1$ \\
\hline Aspartate transaminase; IU $/ L^{1}$ & $123.06 \pm 152.68$ & $140.09 \pm 205.22$ & 0.844 & $<31$ \\
\hline Alanine transaminase; $I U / L^{1}$ & $189.82 \pm 271.73$ & $133.56 \pm 207.81$ & 0.634 & $<31$ \\
\hline Alkaline phosphatase; IU/L ${ }^{2}$ & $320.94 \pm 191.68$ & $307.65 \pm 155.08$ & 0.781 & $64-306$ \\
\hline Serum albumin; $\mathrm{g} / \mathrm{dL}^{2}$ & $3.48 \pm 0.66$ & $3.30 \pm 0.68$ & 0.356 & $3.5-5.4$ \\
\hline Serum protein; $\mathbf{g} / \mathrm{dL}^{2}$ & $6.26 \pm 1.05$ & $6.16 \pm 1.64$ & 0.811 & $6.0-8.3$ \\
\hline Total bilirubin; $\mathrm{mg} / \mathrm{dL}^{1}$ & $2.04 \pm 2.55$ & $4.20 \pm 3.59$ & 0.020 & $0.1-1.2$ \\
\hline Direct bilirubin; mg/dL ${ }^{1}$ & $0.81 \pm 1.13$ & $1.94 \pm 1.69$ & 0.023 & $<0.2$ \\
\hline Blood urea nitrogen; $\mathrm{mg} / \mathrm{dL}^{1}$ & $18.77 \pm 21.68$ & $28.44 \pm 26.51$ & 0.071 & $7-20$ \\
\hline Creatinine; $\mathrm{mg} / \mathrm{dL}^{1}$ & $0.99 \pm 0.37$ & $1.49 \pm 1.70$ & 0.645 & $0.8-1.2$ \\
\hline Blood sugar; mg/dL ${ }^{1}$ & $98.77 \pm 50.55$ & $104.30 \pm 49.95$ & 0.475 & 70-99 \\
\hline Ascitic fluid cell counts; $\mu \mathrm{L}^{1}$ & $587.24 \pm 933.40$ & $2527.72 \pm 7496.39$ & 0.123 & - \\
\hline Ascitic fluid albumin; $\mathrm{g} / \mathrm{dL}^{1}$ & $1.45 \pm 0.50$ & $1.26 \pm 0.75$ & 0.230 & - \\
\hline Ascitic fluid protein; $\mathrm{g} / \mathrm{dL}^{1}$ & $2.02 \pm 0.69$ & $2.00 \pm 1.22$ & 0.480 & - \\
\hline $\mathrm{SAAG}^{2}$ & $2.03 \pm 0.50$ & $2.04 \pm 0.71$ & 0.754 & - \\
\hline $\begin{array}{l}\text { SAAG }^{3} \\
\text { Low } \\
\text { High }\end{array}$ & $\begin{array}{l}0(0.0 \%) \\
17(100.0 \%)\end{array}$ & $\begin{array}{l}3(7.0 \%) \\
40(93.0 \%)\end{array}$ & 0.551 & - \\
\hline MELD score $^{1}$ & $14.65 \pm 7.42$ & $24.00 \pm 10.17$ & $<0.001$ & - \\
\hline
\end{tabular}

PTT partial thromboplastin time, INR international normalized ratio, SAAG serum-ascites albumin gradient, MELD model for end-stage liver disease 'Mann-Whitney test

${ }^{2} T$ test

${ }^{3}$ Chi-square test

normal on imaging $[2,7]$. In our study, most patients were in the chronic BCS group.

The clinical manifestations of BCS are heterogeneous and depend on the extent and speed of the obstruction of the hepatic venous outflow and the presence of collateral venous ducts. All of our participants were symptomatic, although the literature reported that up to $20 \%$ of patients with BCS were asymptomatic [1]. This difference may be due to the fact that all of our participants were referred from other centers for diagnostic and therapeutic procedures and were hospitalized, so we did not evaluate outpatients. Although the classic triad of abdominal pain, ascites, and hepatomegaly is common in BCS patients, other clinical features, including fever, pedal edema, truncal hepatic veins, GI bleeding, and hepatic encephalopathy, may be seen in this disease [1].

In a study by Darwish Murad et al. [10], they found that $61 \%$ and $83 \%$ of patients with BCS had ascites and abdominal pain, while esophageal bleeding and hepatic encephalopathy have been reported in approximately $5 \%$ and $9 \%$ of their patients, respectively. The frequency of all of these manifestations was higher in our results.
$76.7 \%$ of our patients had abdominal pain, while GI bleeding and hepatic encephalopathy in our participants was about $15 \%$, but there was no significant difference in terms of these manifestations between acute and chronic BCS. Another complication of liver failure is spontaneous bacterial peritonitis, which was significantly higher in our study in the chronic group than in the acute group.

In a study conducted by Mahmoud et al. [11] on BCS patients, the frequency of abdominal pain (84\%) and hepatic encephalopathy (36\%) was higher than our results, while the frequency of peripheral edema (4\%), GI bleeding (9\%), jaundice 4 (9\%), and vomiting (27\%) was less than our study. According to clinical manifestations, in our research, the presence of jaundice in chronic BCS was significantly higher than acute group, but there was no significant difference in other clinical features including peripheral edema, and fever between two groups (Tables 2 and 4).

Serum aminotransferases, alkaline phosphatase, serum albumin, serum bilirubin, and prothrombin may be normal or high in patients with BCS [12]. In our 
Table 4 Robust Poisson regression models estimating prevalence ratio (PR) and 95\% confidence interval (Cl) to evaluate the association of various independent variables on the types of Budd-Chiari syndrome

\begin{tabular}{|c|c|c|c|c|}
\hline \multirow[t]{2}{*}{ Variable } & \multicolumn{2}{|l|}{ Crude model } & \multicolumn{2}{|l|}{ Adjusted model } \\
\hline & PR $(95 \% \mathrm{Cl})$ & $P$ value & PR (95\% CI) & $P$ value \\
\hline Gender & & 0.209 & & 0.739 \\
\hline $\begin{array}{l}\text { Female } \\
\text { Male }\end{array}$ & $\begin{array}{l}0.921(0.810-1.047) \\
1.0\end{array}$ & & $\begin{array}{l}1.022(0.897-1.165) \\
1.0\end{array}$ & \\
\hline Age & $1.003(0.999-1.008)$ & 0.144 & $1.001(0.996-1.005)$ & 0.706 \\
\hline Jaundice & & $<0.001$ & & $<0.001$ \\
\hline $\begin{array}{l}\text { Yes } \\
\text { No }\end{array}$ & $\begin{array}{l}1.274(1.123-1.444) \\
1.0\end{array}$ & & $\begin{array}{l}1.308(1.148-1.490) \\
1.0\end{array}$ & \\
\hline Vomiting & ss & 0.154 & & 0.094 \\
\hline $\begin{array}{l}\text { Yes } \\
\text { No }\end{array}$ & $\begin{array}{l}0.912(0.803-1.035) \\
1.0\end{array}$ & & $\begin{array}{l}0.904(0.803-1.018) \\
1.0\end{array}$ & \\
\hline Encephalopathy & & 0.111 & & 0.569 \\
\hline $\begin{array}{l}\text { Yes } \\
\text { No }\end{array}$ & $\begin{array}{l}1.109(0.977-1.261) \\
1.0\end{array}$ & & $\begin{array}{l}1.039(0.911-1.184) \\
1.0\end{array}$ & \\
\hline Gastrointestinal bleeding & & 0.047 & & 0.114 \\
\hline $\begin{array}{l}\text { Yes } \\
\text { No }\end{array}$ & $\begin{array}{l}1.130(1.002-1.275) \\
1.0\end{array}$ & & $\begin{array}{l}1.087(0.980-1.206) \\
1.0\end{array}$ & \\
\hline Renal failure & & 0.017 & & 0.826 \\
\hline $\begin{array}{l}\text { Yes } \\
\text { No }\end{array}$ & $\begin{array}{l}1.150(1.026-1.289) \\
1.0\end{array}$ & & $\begin{array}{l}1.014(0.893-1.152) \\
1.0\end{array}$ & \\
\hline Spontaneous bacterial peritonitis & & $<0.001$ & & 0.001 \\
\hline $\begin{array}{l}\text { Yes } \\
\text { No }\end{array}$ & $\begin{array}{l}1.183(1.100-1.271) \\
1.0\end{array}$ & & $\begin{array}{l}1.289(1.115-1.489) \\
1.0\end{array}$ & \\
\hline Cigarette smoking & & 0.099 & & 0.911 \\
\hline $\begin{array}{l}\text { Yes } \\
\text { No }\end{array}$ & $\begin{array}{l}1.111(0.980-1.258) \\
1.0\end{array}$ & & $\begin{array}{l}0.992(0.865-1.138) \\
1.0\end{array}$ & \\
\hline Alcohol use & & 0.017 & & 0.208 \\
\hline $\begin{array}{l}\text { Yes } \\
\text { No }\end{array}$ & $\begin{array}{l}1.150(1.026-1.289) \\
1.0\end{array}$ & & $\begin{array}{l}1.075(0.961-1.204) \\
1.0\end{array}$ & \\
\hline
\end{tabular}

Table 5 Robust Poisson regression models estimating prevalence ratio (PR) and 95\% confidence interval (Cl) to evaluate the association of various laboratory parameters on the types of Budd-Chiari syndrome

\begin{tabular}{|c|c|c|c|c|}
\hline \multirow[t]{2}{*}{ Variable } & \multicolumn{2}{|l|}{ Crude model } & \multicolumn{2}{|l|}{ Adjusted model } \\
\hline & PR $(95 \% \mathrm{Cl})$ & $P$ value & PR $(95 \% \mathrm{Cl})$ & $P$ value \\
\hline$\overline{\mathrm{PTT}}$ & $1.004(1.001-1.006)$ & 0.003 & $1.002(1.000-1.005)$ & 0.086 \\
\hline INR & $1.037(1.013-1.062)$ & 0.002 & $0.953(0.918-0.989)$ & 0.012 \\
\hline Platelet & $1.000(1.000-1.000)$ & 0.009 & $1.000(1.000-1.000)$ & 0.083 \\
\hline Total bilirubin & $1.021(1.005-1.038)$ & 0.012 & $1.001(0.980-1.022)$ & 0.961 \\
\hline Blood urea nitrogen & 1.002 (0.999-1.004) & 0.139 & $0.996(0.993-1.000)$ & 0.039 \\
\hline Ascitic fluid cell counts & $1.000(1.000-1.000)$ & 0.005 & $1.000(1.000-1.000)$ & 0.326 \\
\hline Ascitic fluid albumin & $0.951(0.868-1.042)$ & 0.281 & $0.978(0.894-1.071)$ & 0.638 \\
\hline MELD score & $1.010(1.005-1.015)$ & $<0.001$ & $1.024(1.012-1.037)$ & $<0.001$ \\
\hline
\end{tabular}

PTT partial thromboplastin time, INR international normalized ratio, MELD model for end-stage liver disease 


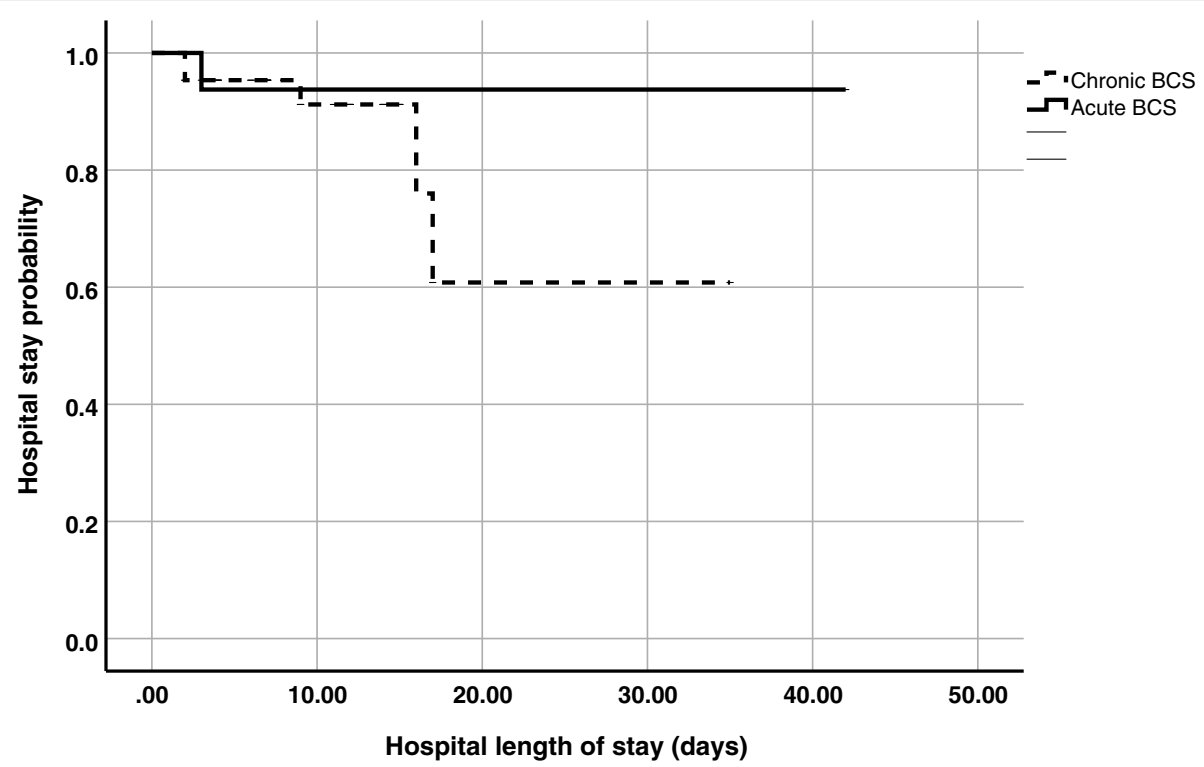

Fig. 1 Kaplan-Meier graph showing hospital length of stay curves for patients with acute and chronic Budd-Chiari syndrome (BCS)

participants, although the mean ALT, AST, bilirubin, INR, and PTT were high in both acute and chronic groups, the differences between the two groups were significant only in bilirubin, INR, and PTT. In a study by Rautou et al. [13], in 96 BCS patients, they concluded that high levels of ALT reflected acute and severe but potentially reversible ischemic liver cell necrosis. Another study of $45 \mathrm{BCS}$ patients who were admitted to four medical centers concluded that serum ALT appeared to be a prognostic indicator [14]. Serum creatinine levels can also be high, usually due to pre-renal dysfunction [12], and may be associated with patient death [15]. The levels of BUN and creatinine in the chronic group of our patients were higher than acute, which was significant in terms of BUN.

The classic composition of ascitic fluid in BCS is high SAAG (> $1.1 \mathrm{~g} / \mathrm{dL})[1,12]$. All patients with acute BCS in our study had high SAAG ascites, but $7 \%$ of patients in the chronic group had low SAAG ascites (Table 3); the reason for this difference was unclear and requires further research with higher sample size. Although standard laboratory analyzes are of little help in diagnosing BCS, they are useful in predicting the severity of the disease, the likelihood of death, and the possible response to treatment. One of the common prognostic indices in BCS is the MELD score $[1,7]$. MELD score and INR in chronic BCS group of our patients were significantly higher than the acute group (Table 5).

An important limitation in our research was that only symptomatic hospitalized participants were studied, so the results of this study may not be generalizable to asymptomatic patients. Another limitation of our study was that it was conducted in a single center, but the main strength of our research was the optimal evaluation of clinical features as well as the detailed assessment of laboratory parameters in acute and chronic BCS patients.

\section{Conclusions}

The present study found that the spontaneous bacterial peritonitis, jaundice, increased levels of MELD score, INR, and BUN were significantly associated with the chronic group compared with the acute group. The hospital LOS and mortality rate between the two groups did not differ significantly. Further research is recommended to clarify this issue.

\section{Supplementary information}

Supplementary information accompanies this paper at https://doi.org/10. 1186/s43066-020-00058-4.

Additional file 1. STROBE checklist

\section{Abbreviations}

BCS: Budd-Chiari syndrome; MRI: Magnetic resonance imaging; PTT: Partial thromboplastin time; INR: International normalized ratio; BUN: Blood urea nitrogen; SAAG: Serum-ascites albumin gradient; MELD: Model for end-stage liver disease; PR: Prevalence ratio; Cl: Confidence interval; LOS: Hospital length of stay; ALT: Alanine transaminase; AST: Aspartate transaminase; Gl: Gastrointestinal

\section{Acknowledgements}

This study was a part of a MD thesis written by Nemattellah Hajizadegan and was supported by the research Council of Shiraz University of Medical Sciences, Shiraz, Iran (1396-01-01-15890).

Authors' contributions

RN generates the research idea. VM study design. LM study design and data collection. $\mathrm{RN}$ and $\mathrm{NH}$ perform the clinical examination. $\mathrm{NH}$ performs the laboratory analysis. All authors shared in analyzing and interpreting the 
patient data and in writing the manuscript. All authors read and approved the final manuscript.

\section{Funding}

This research did not receive any specific grant from funding agencies in the public, commercial, or not-for-profit sectors.

\section{Availability of data and materials}

The datasets used and/or analyzed during the current study are available from the corresponding author on reasonable request.

\section{Ethics approval and consent to participate}

The institutional review board approved the study

(IR.SUMS.MED.REC.1397.442).

Written informed consent was obtained from all individual participants in the study.

\section{Consent for publication}

Not applicable

\section{Competing interests}

The authors declare that they have no competing interests.

\section{Author details}

'Department of Internal Medicine, School of Medicine, Gastroenterohepatology Research Center, Shiraz University of Medical Sciences, Shiraz, Iran. ${ }^{2}$ Department of Internal Medicine, School of Medicine, Shiraz University of Medical Sciences, Shiraz, Iran. ${ }^{3}$ Department of Clinical Pharmacy, School of Pharmacy, Shiraz University of Medical Sciences, Shiraz, Iran.

\section{Received: 3 July 2020 Accepted: 21 September 2020}

Published online: 12 October 2020

\section{References}

1. Martens P, Nevens F (2015) Budd-Chiari syndrome. United European Gastroenterol J. 3(6):489-500

2. Van Wettere M, Bruno O, Rautou PE, Vilgrain V, Ronot M (2018) Diagnosis of Budd-Chiari syndrome. Abdom Radiol (NY). 43(8):1896-1907

3. Zanetto A, Pellone M, Senzolo M (2019) Milestones in the discovery of Budd-Chiari syndrome. Liver Int. 39(7):1180-1185

4. Grus T, Lambert L, Grusova G, Banerjee R, Burgetova A (2017) Budd-Chiari syndrome. Prague Med Rep. 118(2-3):69-80

5. Cheng D, Xu H, Hua R, Xu K, Lv W, Lu X et al (2015) Comparative study of MRI manifestations of acute and chronic Budd-Chiari syndrome. Abdom Imaging. 40(1):76-84

6. Singh V, Sinha SK, Nain CK, Bambery P, Kaur U, Verma S et al (2000) BuddChiari syndrome: our experience of 71 patients. J Gastroenterol Hepatol. 15(5):550-554

7. Valla DC (2018) Budd-Chiari syndrome/hepatic venous outflow tract obstruction. Hepatol Int. 12(Suppl 1):168-180

8. Copelan A, Remer EM, Sands M, Nghiem H, Kapoor B (2015) Diagnosis and management of Budd Chiari syndrome: an update. Cardiovasc Intervent Radiol. 38(1):1-12

9. Shin N, Kim YH, Xu H, Shi HB, Zhang QQ, Colon Pons JP et al (2016) Redefining Budd-Chiari syndrome: A systematic review. World J Hepatol. 8(16):691-702

10. Darwish Murad S, Plessier A, Hernandez-Guerra M, Fabris F, Eapen CE, Bahr $\mathrm{MJ}$ et al (2009) Etiology, management, and outcome of the Budd-Chiari syndrome. Ann Intern Med. 151(3):167-175

11. Mahmoud AE, Mendoza A, Meshikhes AN, Olliff S, West R, Neuberger J et al (1996) Clinical spectrum, investigations and treatment of Budd-Chiari syndrome. QJM. 89(1):37-43

12. DeLeve LD, Valla DC, Garcia-Tsao G (2009) American Association for the Study Liver D. Vascular disorders of the liver. Hepatology. 49(5):1729-1764

13. Rautou PE, Moucari R, Cazals-Hatem D, Escolano S, Denie C, Douarin L et al (2009) Levels and initial course of serum alanine aminotransferase can predict outcome of patients with Budd-Chiari syndrome. Clin Gastroenterol Hepatol. 7(11):1230-1235
14. Tang TJ, Batts KP, de Groen PC, van Hoek B, Haagsma EB, Hop WC et al (2001) The prognostic value of histology in the assessment of patients with Budd-Chiari syndrome. J Hepatol. 35(3):338-343

15. Parekh J, Matei VM, Canas-Coto A, Friedman D, Lee WM (2017) Acute Liver Failure Study G. Budd-chiari syndrome causing acute liver failure: A multicenter case series. Liver Transpl. 23(2):135-142

\section{Publisher's Note}

Springer Nature remains neutral with regard to jurisdictional claims in published maps and institutional affiliations.

\section{Submit your manuscript to a SpringerOpen ${ }^{\circ}$ journal and benefit from:}

- Convenient online submission

Rigorous peer review

- Open access: articles freely available online

- High visibility within the field

- Retaining the copyright to your article

Submit your next manuscript at $\boldsymbol{\nabla}$ springeropen.com 